Дворников Денис Владимирович

Красинский Владислав Вячеславович

Пучнин Алексей Сергеевич

\title{
КОНЦЕПЦИЯ \\ ЭЛЕКТРОННОГО ОПРОСА ИЗБИРАТЕЛЕЙ ПРИ СБОРЕ ПОДПИСЕЙ В ПОДДЕРЖКУ ВЫДВИЖЕНИЯ КАНДИДАТОВ \\ В ДЕПУТАТЫ (НА ВЫБОРНЫЕ ДОЛЖНОСТИ) (SMS- ВЫДВИЖЕНИЕ)
}

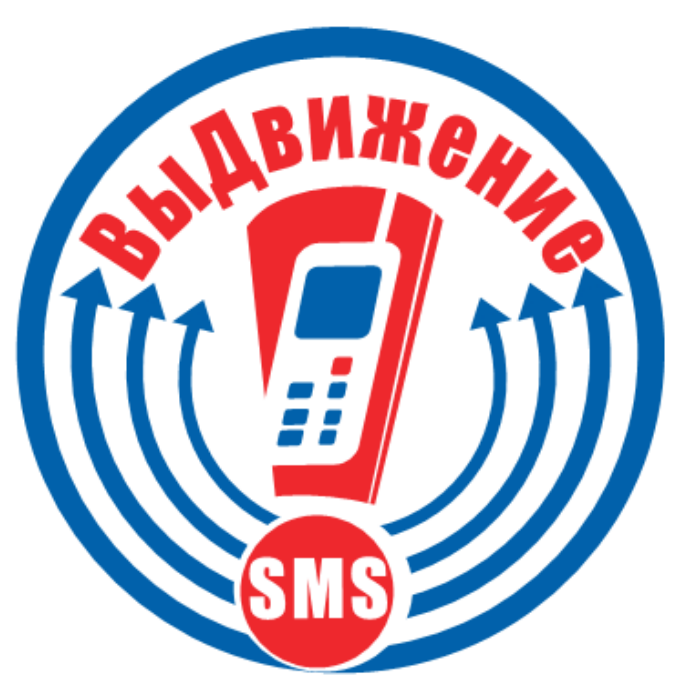

Тамбов 2010 
Источник опубликования: Дворников Д.В., Красинский В.В., Пучнин А.С. Концепция электронного опроса избирателей при сборе подписей в поддержку выдвижения кандидатов в депутаты (на выборные должности) (SMS-ВыДвижение) // Вестник Тамбовского университета. Серия: Гуманитарные науки. Тамбов, 2010. Вып. 9 (87).

В Послании Федеральному Собранию Российской Федерации от 12 ноября 2009 г. Президент Российской Федерации сформулировал концепцию реформирования избирательной системы ${ }^{1}$. Среди инициатив по демократизации выборов Глава государства предложил отказаться в перспективе от сбора подписей как метода допуска к выборам и активизировать работу по техническому переоснащению российской избирательной системы. $\mathrm{B}$ настоящее время реализация предложений Президента Российской Федерации осуществляется в формате внедрения электронных средств для голосования и подсчета голосов. В избирательном процессе используются комплексы электронного голосования, комплексы обработки избирательных бюллетеней, гражданам предоставляется доступ к информации об итогах голосования через мобильную связь. Привязка технического переоснащения избирательной системы исключительно к стадии голосования и подведению его итогов представляется не вполне оправданным. В XXI веке развитие электронной инфраструктуры выборов должно последовательно охватывать все возможные стадии избирательного процесса. Одной из стадий выборов, требующих внедрения современных информационных технологий, является выдвижение и регистрация кандидатов.

Существующая система выдвижения и регистрации кандидатов имеет ряд недостатков, которые влекут за собой многочисленные избирательные споры по поводу отказов в регистрации. В 2007 г. при проведении выборов в законодательные (представительные) органы государственной власти субъектов Российской Федерации судами было рассмотрено 187 избирательных споров, связанных с выдвижением и регистрацией кандидатов (списков кандидатов). По выборам в органы местного самоуправления более 50\% споров касались

\footnotetext{
${ }^{1}$ См. Рос. газ. 2009. 13 ноября.
} 
выдвижения и регистрации кандидатов (списков кандидатов) (279), 26\% из них было удовлетворено ${ }^{1}$. В 2008 г. судами было рассмотрено 257 дел, связанных с проведением выборов в законодательные (представительные) органы государственной власти субъектов Российской Федерации, 53\% из которых (136) касались выдвижения и регистрации кандидатов (списков кандидатов) 2 . На выборах в единый день голосования 11 октября 2009 г. в 76 субъектах Российской Федерации было выдвинуто 94408 кандидатов, из них - в порядке самовыдвижения 39414. По различным основаниям не были зарегистрированы 6655 кандидатов, в том числе 5577 кандидатов, выдвинутых в порядке самовыдвижения ${ }^{3}$.

В действующем законодательстве отсутствует единый подход к оценке указания в подписных листах избыточных сведений о кандидатах. В ряде случаев кандидаты в депутаты (на выборные должности) сталкиваются с разным оформлением справок, направляемых в избирательную комиссию по результатам проверки подписных листов. Заключения экспертов-почерковедов носят субъективно-вероятный характер, имея решающее значение в избирательном процессе: нередко для регистрации кандидату не хватает одной двух подписей в поддержку выдвижения. При повторной проверке подписей суды не всегда допрашивают граждан, объяснения которых противоречат справкам органов Федеральной миграционной службы или заключениям экспертов-почерковедов. Нарушаются положения Федерального закона «Об основных гарантиях избирательных прав и права на участие в референдуме граждан Российской Федерации», региональных законов о выборах, касающиеся порядка приема и проверки подписных листов с подписями

${ }^{1}$ См. Выборы в Российской Федерации. Электоральная статистика 2007. М.: ЦИК России, 2008. С. 172.

${ }^{2}$ См. Выборы в субъектах Российской Федерации 2 марта 2008 года и в единые дни голосования 12 октября 2008 года, 1 марта 2009 года. Электоральная статистика. М.: ЦИК России, 2009. С. 188.

${ }^{3}$ С. Доклад Председателя ЦИК России В.Е. Чурова в Государственной Думе Федерального Собрания Российской Федерации «О прошедших 11 октября 2009 г. выборах в законодательные (представительные) органы государственной власти субъектов Российской Федерации и органы местного самоуправления». 
избирателей, собранными в поддержку выдвижения кандидата, сроков выдачи кандидатам итоговых документов о проверке подписей.

Законодательство о выборах закрепляет в избирательном процессе правовой статус двух неравнозначных кандидатов - «партийного» кандидата и кандидата-самовыдвиженца. Выдвижение кандидата от партии позволяет выдвинутому лицу избегать организационных, материальных и временных затрат на сбор подписей в поддержку выдвижения. Сбор подписей является формой предварительной поддержки неизвестного беспартийного кандидата, которая свидетельствует о его способности конкурировать с кандидатами от партий, представленных в органах государственной власти и местного самоуправления и наделенных предварительной поддержкой избирателя в предыдущих электоральных циклах. Недостаточная подготовленность, невнимательность кандидатов и их представителей при заполнении и оформлении подписных листов, отсутствие единообразной правоприменительной практики проверки подписных листов с подписями избирателей, собранными в поддержку выдвижения кандидатов, порождают значительное число избирательных споров по поводу отказов в регистрации кандидатов.

Эти и другие проблемы нормативного регулирования и правореализации актуализируют вопрос замены традиционного механизма сбора подписей в поддержку выдвижения кандидатов на альтернативные формы подобной работы, отвечающие потребностям современного этапа развития российской избирательной системы.

Одним из вариантов устранения указанных недостатков организации избирательного процесса является процедура SMS-Выдвижения. Количество SMS-сообщений, необходимое для регистрации кандидата, устанавливается законом. Лицо, обладающее активным избирательным правом в избирательном округе, в котором выдвигается кандидат, отправляет SMSсообщение с порядковым номером того или иного кандидата на единый номер интерактивного сервиса с мобильного телефона, зарегистрированного 
на свое имя. Единый номер интерактивного сервиса предоставляется оператором сетей связи и заблаговременно доводится до сведения участников выборов избирательной комиссией субъекта Российской Федерации. Порядковые номера кандидатов определяются избирательной комиссией субъекта Российской Федерации путем жеребьевки с участием представителей средств массовой информации, избирательных объединений, кандидатов в депутаты (на выборные должности). Переданные избирателем данные в поддержку выдвижения кандидата регистрируются оператором сетей связи и незамедлительно передаются соответствующей избирательной комиссии и общественным организациям, контролирующим процедуру поддержки выдвижения кандидатов на выборах. Избирателю, поддержавшему выдвижение кандидата, с помощью SMS направляется подтверждение от оператора сетей связи о том, что выбранный им вариант поддержки учтен, а также сообщается дата и время поступления SMSсообщения избирателя. Учету и регистрации подлежит одно SMS-coобщение, отправленное избирателем в поддержку выдвижения кандидата. Не учитываются: SMS-сообщения, отправленные из информационной телекоммуникационной сети общего пользования «Интернет», SMSсообщения из других субъектов Российской Федерации и зарубежных операторов сетей связи, SMS-сообщения с различных SIM-карт, авторизуемые в сети с одинаковым IMEI (международным идентификатором мобильного телефона). В целях соблюдения требований законодательства Российской Федерации и идентификации граждан, осуществляющих электронную поддержку выдвижения кандидатов, операторы сетей связи (избирательные комиссии) осуществляют документирование действий, связанных с электронным выдвижением кандидатов, при этом обязательному документированию подлежат следующие сведения: фамилия, имя и отчество абонента; дата и год рождения абонента; серия и номер паспорта абонента; гражданство абонента; № мобильного телефона абонента; дата регистрации SIM - карты абонента; IMEI (международный идентификатор мобильного 
телефона) абонента; дата и время поступления SMS-сообщения абонента в поддержку выдвижения. По истечению установленного законом периода выдвижения кандидатов соответствующей избирательной комиссией на основе сведений, предоставленных операторами сетей связи, составляется итоговый протокол, который прилагается к решению избирательной комиссии о регистрации кандидата либо об отказе в регистрации кандидата. Копия итогового протокола передается кандидату, уполномоченному представителю избирательного объединения.

SMS-Выдвижение необходимо рассматривать в качестве одной из перспективных составляющих электронной инфраструктуры организации и проведения выборов. В отличие от электронного голосования поддержка выдвижения кандидатов с помощью SMS-технологий не предполагает сохранения тайны голосования и обеспечения еe защиты, поскольку процедура поддержки выдвижения кандидатов в соответствии с законом связана с добровольным согласием избирателя на предоставление своих персональных данных кандидату.

Использование SMS на стадии выдвижения кандидатов позволяет уменьшить затраты при проведении выборов, использовать новые технологии в целях расширения возможностей участия в выборах людей с ограниченными возможностями, избирателей, проживающих в отдаленных местностях, исключить выборочное правоприменение и элементы «административного ресурса» в деятельности организаторов и участников выборов. Оперативность, удобство и простота использования SMSтехнологий призваны способствовать расширению социальной базы поддержки кандидатов в депутаты (на выборные должности), а также стимулировать рост активности избирателей на выборах разных уровней.

Основными целями внедрения в современную российскую избирательную систему практики SMS-выдвижения являются:

- апробирование организационной и технической возможности процедуры электронной поддержки кандидатов на стадии выдвижения; 
- выявление степени электоральной готовности к использованию мобильных телефонов как альтернативы заполнения подписных листов.

Организаторами и участниками проекта выступают: избирательная комиссия Тамбовской области, Учебный центр «Европейский клуб профессионалов», Центр правовых технологий «Гражданский союз», автономная некоммерческая организация «Юридический Центр «Гарант», РЦОИТ при ЦИК России, Общественный консультативный научнометодический Совет при ЦИК России, средства массовой информации, кандидаты в депутаты (на выборные должности), избиратели.

Организационно-технически SMS-выдвижение предполагает несколько этапов:

- формирование из числа избирателей базы респондентов, готовых дать письменное согласие на участие в эксперименте и получение sms-сообщений на свой мобильный телефон;

- взаимодействие с соответствующими избирательными комиссиями в части получения сведений о выдвижении кандидатов и составления текста sms-сообщения с указанием выдвинувшихся кандидатов;

- использование интерактивного сервиса по рассылке, сбору и сортировке sms -сообщений;

- подведение итогов и формирование аналитического контента для последующей доработки и применения в избирательном процессе.

Пилотный проект SMS-выдвижения сопровождается комплексом социологических исследований политической активности населения, представлений о депутатском корпусе, доверия результатам и способам голосования, существующим механизмам выдвижения кандидатов в депутаты (на выборные должности), отношения к электронному голосованию.

Безопасность и защищенность проекта SMS-выдвижения обеспечена системой мер защиты информации: применением сертифицированных технических средств и средств связи; защитой информации при ее передаче 
по сетям связи; исключением несанкционированного доступа к сведениям об избирателях, участвующих в SMS-поддержке выдвижения кандидатов; обеспечением подлинности и целостности информации в базах данных операторов сетей связи и избирательных комиссий. Операторы сетей связи, ресурсы которых используются при SMS-выдвижении кандидатов, несут ответственность за качество оказываемых услуг.

Контроль за процедурой электронной поддержки кандидатов на стадии выдвижения может осуществляться соответствующей уровню выборов избирательной комиссией путем случайной выборочной проверки подлинности части представленных SMS-сообщений, а также выборочного телефонного опроса избирателей о поддержанной ими кандидатуре. При осуществлении проверки подлинности SMS-сообщений в поддержку выдвижения извещаются кандидаты в депутаты (на выборные должности) и уполномоченные представители избирательных объединений, участвующие в выборах.

Общественный контроль за процедурой электронной поддержки кандидатов на стадии выдвижения связан с участием общественных организаций в реализации проекта SMS-выдвижения и возможностью проверки процесса (правильности ввода данных) и результатов SMSвыдвижения в online-режиме на сайтах общественных организаций участников проекта.

Представляется, что результаты электорального эксперимента позволят сделать выводы об отношении населения к внедрению электронных технологий в избирательную систему Российской Федерации и потенциале доверия избирателей к SMS-голосованию, выявить перспективы SMSвыдвижения в контексте развития электронных технологий российской избирательной системы. 